\title{
Coupled wave and surge modelling and implications for coastal flooding
}

\author{
J. Wolf \\ Proudman Oceanographic Laboratory, Joseph Proudman Building 6, Brownlow Street Liverpool, L3 5DA UK
}

Received: 15 January 2008 - Revised: 25 March 2008 - Accepted: 15 May 2008 - Published: 20 June 2008

\begin{abstract}
The physical causes of coastal flooding due to marine storms are discussed. We examine the costs and impacts of storm surges and waves with reference to the UK. The mechanisms of interaction between waves and the mean circulation due to tides and wind are reviewed. A case study to illustrate the magnitude of surges, waves and their interactions is presented for Liverpool Bay in the eastern Irish Sea. Applications of surge and wave models to the Mediterranean, especially the Adriatic Sea, are considered.
\end{abstract}

\section{Introduction}

Coastal flooding is caused by a combination of high water levels, which may be caused by tides and storm surges, often accompanied by high waves, which lead to overtopping of coastal defences and inundation of low-lying areas, potentially causing damage to life and property. Waves and storm surges are caused by storms with high winds blowing over the adjacent sea. There is a concern that, due to global warming, mean sea level will rise and the intensity of storms may increase and hence the incidence of coastal flooding may also increase. There is also an increased risk due to socio-economic factors leading to more people to live in flood risk areas (coastal and flood plains), see e.g Hall et al. (2007). The UK, in common with many other countries, has assets worth billions of pounds at risk from coastal floods, river floods, and coastal erosion. Here we only address the physical mechanisms causing coastal flooding. Areas of the UK at risk include the low-lying coasts of SE England from Norfolk to the Thames Estuary, including central London which is protected by a storm surge barrier, as well as other parts of England and Wales e.g. the eastern Irish Sea.

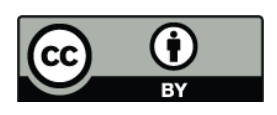

Correspondence to: $\mathrm{J}$. Wolf (jaw@pol.ac.uk)
One of the worst cases of flooding in the UK in recent history was in 1953 when about 300 people died in SE England and over 1800 in the Netherlands (Gerritsen, 2005). The 1953 storm generated a large storm surge (2-3 m on English coast, $>3 \mathrm{~m}$ on Dutch coast), which combined with a high spring tide to produce particularly high sea levels. The track of the storm brought exceptionally strong northerly winds over shallow areas of the western and southern North Sea where the main surge effect was generated. The elongation of the storm to the north also produced a long fetch and generated large wind waves. Waves in the southern North Sea reached about $10 \mathrm{~m}$ significant wave height (Wolf and Flather, 2005).

Assuming the current level of flood defences is not improved, the financial cost of one of the "1953 type" storm surge scenarios would rise by around $150 \%$ to between $£ 7.5$ billion and $£ 16$ billion (for current exposure and values) with a sea level rise of $0.4 \mathrm{~m}$. A recent study by the Association of British Insurers (ABI) showed that maintaining levels of risk comparable with those today would cost £3.74.6 billion in improving defenses and flood risk management (http://www.rms.com/NewsPress/PR_110906_ABI.asp). The UK government Department of Food and Rural Affairs (DEFRA) sets the policy on coastal flooding with the Environment Agency (EA) as its operational agency. The EA introduced a national flood and coastal defence database in 2003 (Hall et al., 2007). The UK storm tide forecasting service (STFS) runs operational forecasts of sea level due to tides and surges twice daily at the UK Met Office which may lead to evacuation of low-lying coastal areas if necessary e.g. on 9 November 2007 (http://www.metoffice.gov.uk/corporate/ pressoffice/2007/pr20071109.html). Hall et al. (2007) also address the quantification of future flood risk for England and Wales. Previously it was assumed that flood statistics were stationary; now it is recognized that there is a trend in sea level and possibly in wind forcing and flood management rather than flood prevention is the priority.

Published by Copernicus Publications on behalf of the European Geosciences Union. 


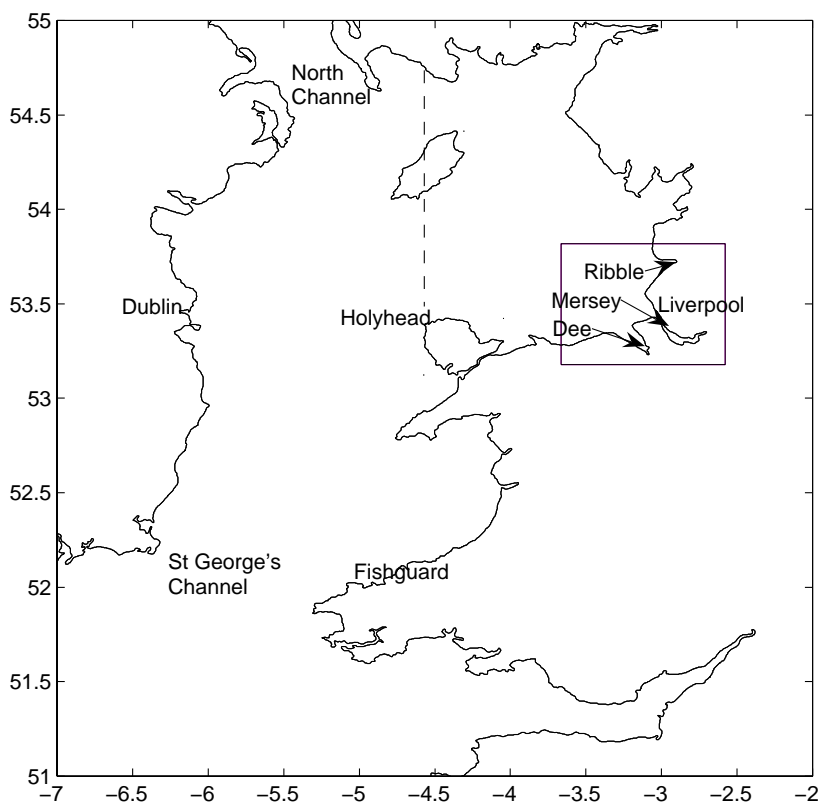

Fig. 1. Map of Irish Sea, from St George's Channel to North Channel. Dotted line delineates extent of eastern Irish Sea. Solid line shows area of Liverpool Bay model.

Surge models are also run in other countries around the North Sea (Flather, 2000). Wave and storm surge predictions are still made separately in most operational centres although there is an increasing movement towards using coupled models (Ozer et al., 2000). These models are generic e.g. Wakelin and Proctor (2002) applied a surge-tide model developed for the UK to the Mediterranean.

Surges in UK waters are generally caused by strong winds in mid-latitude depressions passing over the UK from the Atlantic. Wind stress is particularly effective in piling up water against the coast in the shallow water of the continental shelf as the effect is inversely proportional to water depth. Depths in the southern North Sea and the eastern Irish Sea are only about $40 \mathrm{~m}$ on average. Around the UK the surge typically behaves as a forced Kelvin wave (Gill, 1982). The inverse barometer effect of atmospheric pressure is important in deeper water e.g. the Mediterranean. The principles of wave and surge generation by wind are universal, although the impacts vary in different geographical locations. Surges in the Mediterranean as a whole are likely to be much lower due to the much deeper water. However they are important in local areas of shallow water e.g. the Northern Adriatic, where Venice is susceptible to flooding. A scheme to defend the city with gates is now in construction, although it is quite controversial (Pirazzoli and Umgiesser, 2003). In the Adriatic the wind tends to trigger the 22-h seiche (Gill, 1982) and its harmonics e.g. 11-h and 7-h oscillations. The operational forecast system for Venice is still based on statistical models since their skill is not yet matched by hydrodynamic mod- els. Problems may arise due to errors in the forecast wind field and seiches (Lionello et al, 1998; Wakelin and Proctor, 2002). A combined surge and wave prediction model is described by Bargagli et al. (2002) who show that prediction of surges in the Adriatic is improved by modelling the whole Mediterranean due to better representation of the principal modes and the pressure effect.

We now discuss the physical mechanisms causing wavetide-surge interaction and, as an illustration, discuss waves and surges in Liverpool Bay in the eastern Irish Sea.

\section{Wave-tide-surge interactions}

It has long been recognised that in shallow water areas with a large tidal range, the nonlinear effects of tide-surge interaction are important. The maximum of the observed surge (total water level minus predicted tide) for a surge event tends to 'avoid' predicted tidal high water, due to the speeding up of the tidal wave propagation in the deeper water caused by the surge elevation (other subtle changes are caused by nonlinear bottom friction and the interaction of tide- and surgegenerated currents). The mechanisms are discussed in detail in Wolf (1981), see also Horsburgh and Wilson (2007). Water depth exerts a strong control on coastal waves, so that at high water the waves are larger and also reach further inland. Sutherland and Wolf $(2001,2002)$ studied the combined effect of water level and waves in overtopping coastal defences, including interactions and the projected effect of climate change to 2075 . They concluded that is will be necessary to raise defences by more than the predicted rise in sea level to maintain the same level of risk. More recently the effects of waves on surges (as well as the effects of the tide and surge on waves) has been studied, identifying coupling mechanisms affecting depth and current refraction, surface stress and bottom friction (Wolf, 2004; Osuna and Wolf, 2005). Although tides are generally very small in the Mediterranean, tide-surge interaction may also be locally important.

In recent years the improvement in computer capability has allowed high-resolution 3-dimensional models of tides and surges to be developed (Jones and Davies, 1998) and increasingly coupled with wind-wave models (Osuna and Wolf, 2005).

\section{Case study: waves and surges in Liverpool Bay}

The shallow north-eastern part of the Irish Sea is particularly susceptible to storm surges. Lennon (1963) suggested that major west coast storm surges are caused by Atlantic secondary depressions passing from SW to NE over the northern part of the British Isles at a critical speed of about 40 knots. It is in the right-rear quadrant of the cyclone that surge-generating forces attain their maximum efficiency. We 
examine particularly the Liverpool Bay area, adjacent to the port of Liverpool in the eastern Irish Sea (Fig. 1).

During the night of 11th and 12th November 1977 severe storms coinciding with high tides overtopped coastal defences throughout Lancashire and Cumbria. Simulations of the November 1977 surge event (Davies and Jones, 1998) show that for surges in Liverpool Bay the flow into the Irish Sea through the North Channel and Celtic Sea (the external surge) is about equally important as the locally generated surge. Also it is necessary to have a high enough grid resolution and good representation of the spatial variability of the wind, to correctly reproduce the surge event at Liverpool. They also conclude that wave-current interaction can be significant.

The coupled POLCOMS-WAM (surge-tide-wave) and SWAN wave model with time-varying water level and currents have been used to simulate wind-driven waves and surges in the Irish Sea and Liverpool Bay (Osuna and Wolf, 2005; Sutherland and Wolf, 2001; Wolf, 2007). The largest waves and surges in Liverpool Bay are generated by westerly and north-westerly winds.

Tide and surge effects are not totally independent as there are interactions between them, as discussed above, and the maximum surge at Liverpool generally does not fall on high water (Woodworth and Blackman, 2002). For the purpose of coastal flooding it is the maximum of total water level which is important. The surge is often defined as a residual of (tide plus surge) minus predicted tide, which then puts the interaction component into the surge residual. The maximum tidal range at Liverpool exceeds $10 \mathrm{~m}$ and thus dominates in terms of the timing of the peak of total water level (Woodworth and Blackman, 2002). Further analysis of the joint probability of surge and tide is discussed for example in Pugh (2004). Extreme water levels at Liverpool were investigated by Dixon and Tawn (1995) using various joint probability methods. The 1 in 100 year extreme level for Liverpool is about $5.9 \mathrm{~m}$ above Ordnance Datum Newlyn (ODN, which is close to mean sea level) which is less than the sum of the highest astronomical tide (HAT) and maximum possible surge contribution thus illustrating that the maximum surge tends to avoid high tide (HAT $=5.36 \mathrm{~m}$ ODN). The seven largest surges at Liverpool between 1920 and 1955 all exceeded 1.5m (Lennon, 1963) and the November 1977 surge was nearly $2 \mathrm{~m}$ at Liverpool (Jones and Davies, 1998). From Hinton et al. (2007) the 1:50 year surge exceeds $1.75 \mathrm{~m}$. Interestingly, Woodworth and Blackman (2002) found that extreme surges in the Irish Sea were found to be more common in the decades starting 1900 and 1970 than at other times in the 20th century (although with incomplete information for the 1990s). This is presumably due to inter-annual and decadal changes in the wind climate.

Liverpool Bay is sheltered from swell waves from the Atlantic and experiences locally wind-generated sea. Waves have been recorded in Liverpool Bay from November 2002 to the present and also in 1965-1966 (Wolf, 2007). The

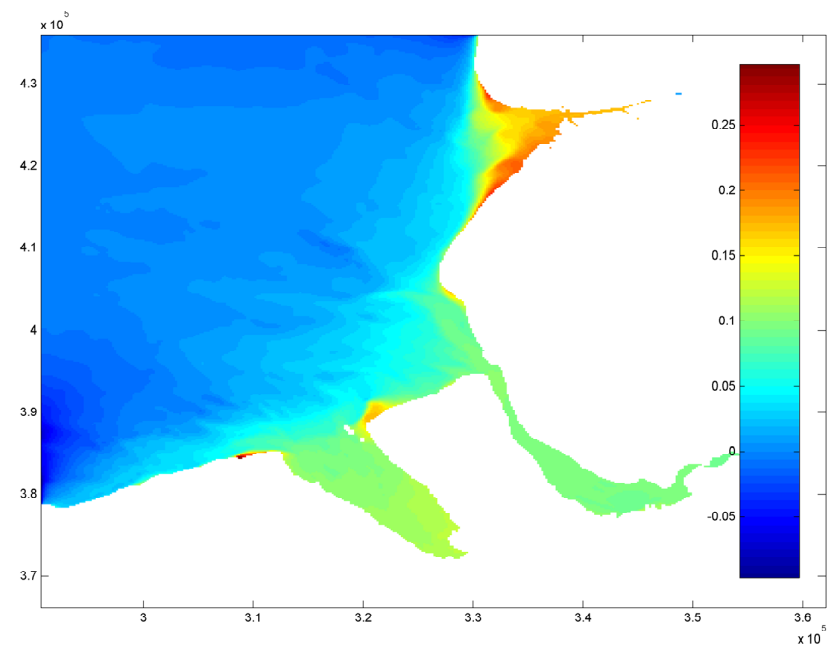

Fig. 2. Wave setup (m) over Liverpool Bay for $20 \mathrm{~m} / \mathrm{s} \mathrm{NW}$ wind at MHWS.

wave height typically exceeds $3 \mathrm{~m}$ during 5-10 events per year and exceeds $4 \mathrm{~m}$ from $1-5$ times per year. There is a lot of inter-annual variability but the 1:50 year wave height is about $5.5 \mathrm{~m}$ using the data from 2002-2006.

Wave setup has been calculated in the SWAN model (from the gradient of the radiation stress) for the case of a steady $20 \mathrm{~m} / \mathrm{s} \mathrm{NW}$ wind for the mean high water spring (MHWS) tide (Fig. 2). This represents quite a severe storm on a high spring tide. The total water level may be assumed uniform over the model area as the tidal phase is almost coincident. The maximum wind-stress, using Smith and Banke (1975) is $1.13 \mathrm{Nm}^{-2}$ and the offshore wave height reaches $5.5 \mathrm{~m}$. The local surge is then predicted to be $0.5 \mathrm{~m}$ and the external surge may be of the same magnitude (Jones and Davies, 1998). In some areas wave setup reaches $0.3 \mathrm{~m}$. The areas in which setup is greatest depend on the water depth and bottom slope. At Liverpool it is calculated as $0.10-0.15 \mathrm{~m}$ which is more than $10 \%$ of the maximum surge. The areas most affected match those identified in the EA flood risk maps (http://maps.environment-agency. gov.uk/wiyby/mapController). Other interaction effects due to current refraction, surface and bottom stress have been estimated to produce the same order of magnitude effect on wave height and up to $20 \%$ change in wave period (Osuna and Wolf, 2005).

\section{Summary}

This paper has given an overview of the causes and impacts of waves and surges and their interactions with an illustrative case study for Liverpool Bay where the effect of wavetide-surge interactions can be demonstrated to be large. The effect of wave setup on still water level may reach $10 \%$ of the wind-driven surge level. The maximum surge tends not 
to coincide with high tide and wave-surge-tide interaction should be taken into account for an accurate prediction of coastal flooding. The implications for coastal flooding and coastal erosion are important, especially in the light of the costs of increasing coastal defences due to the expected effects of climate change (Hinton et al., 2007). The models which have been used are generic and similar models can be applied to the Mediterranean, where it is expected that surge and wave coupling will also be important for coastal flooding in low-lying areas.

Acknowledgements. Thanks to Kevin Horsburgh for commenting on the manuscript.

Edited by: A. Mugnai

Reviewed by: one anonymous referee

\section{References}

Bargagli, A., Carillo, A, Mariotti, A., Pisacane, G., Ruti, P. M., and Struglia, M. V.: An integrated forecast system over the Mediterranean basin: extreme surge prediction in the northern Adriatic Sea, Mon. Weather Rev., 130, 1317-1322, 2002.

Flather, R. A.: Existing operational oceanography, Coast. Eng., 41, 13-40, 2000.

Gerritsen, R. A.: What happened in 1953? The Big Flood in the Netherlands in retrospect, Phil. Trans. R. Soc. A 363, 12711291, 2005.

Gill, A. E.: Atmosphere-Ocean Dynamics, Academic Press, 662 pp., 1982.

Hall, J. W., Sayers, P. B., Panzeri, M. and Deakin, R.: Quantitative assessment of driver impacts on future flood risk in England and Wales, Chap. 13 in: Future flooding and coastal erosion risks, edited by: Thorne, C. R., Evans, E. P., and Penning-Rowsell, E. C., Thomas Telford, 514 pp., 2007.

Hinton, C., Townend, I. H., and Nicholls, R. J.: Coastal Processes, Chap. 9 in: Future flooding and coastal erosion risks, edited by: Thorne, C. R., Evans, E. P., and Penning-Rowsell, E. C., Thomas Telford, 514 pp., 2007.

Horsburgh, K. J. and Wilson, C.: Tide-surge interaction and its role in the distribution of surge residuals in the North Sea, J. Geophys. Res., 112, C08003, doi:10.1029/2006JC0040332007

Jones, J. E. and Davies, A. M.: Storm surge computations for the Irish Sea using a three-dimensional numerical model with wavecurrent interaction, Cont. Shelf Res., 18, 201-251, 1998.
Lennon, G. W.: The identification of weather conditions associated with the generation of major storm surges along the west coast of the British Isles, Q. J. Roy. Meteor. Soc., 89, 381-394, 1963.

Lionello, P., Zampato, L., Malguzzi, P.,Tomasin, A., and Bergamasco, A.: On the correct surface stress for the prediction of the wind wave field and the storm surge in the northern Adriatic Sea, Nuovo Cimento, 21C, 515-531, 1998.

Osuna, P. and Wolf, J.: A numerical study on the effect of wavecurrent interaction processes in the hydrodynamics of the Irish Sea, In Proceedings of the 5th. International Conference on Ocean Wave Measurement and Analysis: WAVES2005, 3rd to 7th July, 2005, Madrid, Spain, 2005.

Ozer, J., Padilla-Hernández, R., Monbaliu, J., Alvarez Fanjul, E., Carretero Albiach, J. C., Osuna, P. Yu, J. C. S. and Wolf, J.: A coupling module for tides, surges and waves, Coast. Eng., 41, 95-124, 2000.

Pirazzoli, P. A. and Umgiesser, G.: Is the "MOSE" project to save Venice already obsolete?, Geophys. Res. Abstr., 5, 03393, 2003.

Pugh, D. T.: Changing Sea Levels: Effects of Tides, Weather and Climate, Cambridge University Press, 2004.

Smith, S. D. and Banke, E. G.: Variation of the sea surface drag coefficient with wind speed, O. J. Roy. Meteor. Soc., 101, 665673, 1975.

Sutherland, J. S. and Wolf, J.: Coastal defence vulnerability 2075. $36^{\text {th }}$ Conference of River and Coastal Engineers, Keele University, June 20-22, 2001.

Sutherland, J. S. and Wolf, J.: Coastal defence vulnerability 2075, HR Wallingford Report SR590, 2002.

Wakelin, S. L. and Proctor, R.: The impact of meteorology on modelling storm surges in the Adriatic Sea, Global Planet. Change, 34, 1, 97-119, 2002.

Wolf, J.: Surge-tide interaction in the North Sea and River Thames, 75-94, in: Floods due to high winds and tides, edited by: Peregrine, D. H., 1981.

Wolf, J.: Coupling waves and currents in POLCOMS with measurements from the coastal observatory. Annales Hydrographiques, 6th Ser., 3, 772, 9-1-9-3, 2004.

Wolf, J. and Flather, R. A.: Modelling waves and surges during the 1953 storm, Phil. Trans. R. Soc. A, 363, 1359-1375, 2005.

Wolf, J.: Wave climate in Liverpool Bay POL Internal Document No., 187, 27 pp., 2007.

Woodworth, P. L. and Blackman, D. L.: Changes in extreme high waters at Liverpool since 1768, Int. J. Climatol., 22, 697-714, 2002. 